\title{
Development of Parent-Educator Cooperation in Public Preschool Institutions: Case Study
}

\author{
Rozafa Ferizi-Shala \\ PhD candidate at the Faculty of Social Science, University of Tirana, Albania \\ Teaching assistant at the Faculty of Education, University of Prishtina, Kosova \\ Email: rozafa.ferizi-shala@uni-pr.edu
}

\author{
Doi:10.5901/mjss.2017.v8n1p237
}

\begin{abstract}
This study addresses the issue of cooperation between parents and educators in public preschool institutions in Kosovo. Cooperation is a process developed by both sides and the educator and parents should contribute consistently on it. The purpose of the study is to see how communication takes place between parents and preschool institutions and identification of the extent of involvement of parents in order to create a stable cooperation with the institution. Data were collected through questionnaires, distributed to parents who had their children enrolled in preschool institutions from the age of 5-6 years old. The participation of parents in the study was on voluntary bases. From the result analyses it was noticed that parents are more involved in activities requiring for their assistance and indirect help while the active participation of the family in all forms of work organization in preschool institutions is not very evident. The overall findings of this study encourage preschool institutions to develop a comprehensive plan for greater involvement of family in the work developed within the institution, and for parents as well to increase the level of interest in the work taking place in preschool institutions.
\end{abstract}

Keywords: Preschool education, Preschool teacher, Parents, Cooperation, Involvement,

\section{Introduction}

Institutionalized preschool education is characterized by a range of characteristics that make it often specific and difficult to be always relevant and in line with the present demands. Given the fact that preschool education in Kosovo continues to be on voluntary bases and it is not mandatory, quality preschool education and aligned with the standards required is not in the focus of policymakers and decision makers in our country. Although based on Kosovo Education Strategic Plan 2011-20016 (2011) the overall objective of preschool education is to provide inclusive and equitable access for all children to quality, non-discriminating education up to the age of 6 by 2016, through increasing the capacity of the physical infrastructure, campaigns for raising awareness, enhancing curriculum and learning materials and initiating programmes for professional development of educators and administrative staff. (MASHT, p. 58). This has not been accomplished yet, and there is quite a low percentage of inclusion of children of age 3-5 years in preschool institutions. Inclusion of children in institutionalized preschool education continues to be a challenge for our country.

As for the increase of cooperation and interaction with the family, according to the Kosovo Education Strategic Plan 2011-2016 (2011) parents and communities should be aware of the importance of early childhood education through ongoing campaigns, seminars, trainings and other activities (p. 58) which should have taken place during a 5 year period since this strategy in its priorities foresees also "development of guidelines for greater involvement and inclusion of the family in improvement and evaluation of preschool education programmes." (MASHT, 2011, p. 58). Pursuant to Law on Preschool Education (2006) parents' participation refers to parents' involvement in arrangements made by preschool institutions in order to help and contribute in effectiveness of decisions in educating their children, activities which support the curriculum of those who assist in preschool institutions activities (p. 3).

But, are preschool institutions using their human resources to the extent necessary, in order to improve the work that takes place in preschool institutions. In here as well we may certainly say that preschool institutions have not yet managed to establish a good line of communication with all potential partners for cooperation, starting with the parents to expand gradually further on with other potential cooperation partners.

\section{Literature Review}

One of the more important pillars of preschool education in general is family involvement in all levels of work organisation 
within the institution. According to Rimm-Kaufman \& Pianta (1999) family involvement operates in many levels within family, schools and community. Therefore it is necessary for the process to be organized.

According to Sandberg and Vuorinen (2008) it is important for preschool teacher to provide varied and rich forms of cooperation, as different forms of cooperation appeal to different parents. With the wide range, there is a possibility to reach all parents. Teachers need to have a cooperation plan which would help them in involving parents in the work of institution. At the same time family involvement is quite specific and multidimensional.

Hornby (2011) in his book on parental involvements explains that the types of parental involvement found to be most engaged in by the schools surveyed were as follows: various informal activities for encouraging parents to come to school, varied formats of parent-teacher meetings, both formal and informal, a variety of forms of written communication, telephone contacts and to a lesser extent use of new technological options, and home visits. All these forms of communication may be suitable in certain situations with certain parents. But the usage of many forms of cooperation is an opportunity more for active participation of the family in the activity organized in preschool institutions. Parents often lack information that their right for active involvement in the institution is missing, others believe that with the selection of parent boards all the responsibility passes on the parents involved in decision making. Therefore it is very important for the preschool institutions to inform parents previously about the possibility of their involvement in activities taking place at the preschool institution and then try to gradually create bridges of cooperation based on a constructive and suitable communication for each family in particular. According to Leithwood (2009)(1999) there are three sets of factors contribute to poor parent-school communications, tense relations between parents and school personnel and frustrations for parents arising from the school: dispositions towards parent engagement on the part of parents and school personnel; the nature of school-parent communications; and both linguistic and cultural differences between parents and staff. ( $p$. 12) (p. 12). Due to lack of meaningful and sustainable communication between family and preschool institutions barriers still exist and constantly impede the establishment of an inclusive and sustainable partnership between them. Henrich \& Blackman-Jones (2006) suggests that the partnership can lead to better understanding of the dynamics of parent involvement and can further the development of effective strategies for including parents in their children's preschool education (pp. 149-150).

Epstein's framework of six types of involvement for comprehensive programs of partnership includes those types: parenting, communicating, volunteering, learning at home, decision making and collaborating with the community helps educators develop more comprehensive programs of school and family partnerships (Epstein, 2002). These six types can serve as a basic model for building partnership between the preschool institution and family, when is it known that not every form of cooperation chosen by the preschool institution may fit the possibilities each family has to get involved in the activity taking place in preschool institutions. Also based in Epstein studies those six types of involvement can guide the development of a balanced, comprehensive program of partnerships, including opportunities for family involvement at school and at home, with potentially important results for students, parents, and teachers. The results for students, parents, and teachers will depend on the particular types of involvement that are implemented, as well as on the quality of the implementation (Epstein, 2002, p. 30).

Based on general goals of the preschool institution and the program used, in their philosophy they promote various forms of establishing partnership with parents. The approach the preschool institution applies in regards to active involvement of parents in the activity of preschool institution and the program the institution implements, may favour or disfavour the cooperation with parents. Also the study by Rimm-Kaufman \& Pianta (1999) argues that: "teacher-family contact differed among various preschool and kindergarden programes reflecting different program philosophies and priorities" (p.433). Currently in our country we cannot talk for a working program that follows a certain philosophy or has a development line, since the working program implemented is a combination of traditional forms of work based on teachercentred teaching and the "Step by Step" program, which is based on and promotes student-centred philosophy, approaches which do not have many elements in common. However, numerous studies support the idea that the partnership between a preschool institution and families is quite beneficial and it offers long term benefits in holistic development of children. Therefore the purpose of the study is to see how communication between parents and preschool institutions is done and identifying the level of involvement of parents in order to create a stable cooperation with the Preschool Institution for the best of children.

\section{Methodology}

The study is done with parents from two public preschool institutions located in urban areas and with the parents of a preprimary class located in a rural area. Almost all rural areas in Kosovo lack full-day preschool institutions and the approach of a child with institutionalized education begins at the age of 5 , when the child begins preprimary classes 
located within the premises of primary school located in that village. In some bigger villages there are Community Based Centers, but their number is quite small.

Since in preschool institutions we have children from 0.6 months - up to 6 years old, while in preprimary classes children of 5-6 years old only. In preschool institutions are involved only parents whose children were of 5-6 years old, aiming to create same group with the parents in rural areas, whose children were of age 5-6 years old.

Participation in the study was done on voluntary bases and it was not mandatory for parents. The study involved a total of 64 parents, as per the institutions presented in the table below.

Table 1. Parents participating in the study

\begin{tabular}{lcccc}
\hline & Frequency & Percentage & Valid Percentage & Cumulative Percentage \\
\hline Preschool Institution (1) Urban area & 18 & 28.1 & 28.1 & 28.1 \\
Preprimary Classes (2)-Rural Area & 14 & 21.9 & 21.9 & 50.0 \\
Preschool Institution (3) Urban Area & 32 & 50.0 & 50.0 & 100.0 \\
Total & 64 & 100.0 & 100.0 & \\
\hline
\end{tabular}

\section{Data Collection}

Data for this study were collected through a questionnaire, with the questions divided into informative session and six other sessions. Information from the literature used for the study, with special emphasis from studies by Epstein and others, were used to develop the questionnaire. Questionnaire applies to the context in which the study was done.

The questionnaire was distributed to parents by educators, at the time when they were picking up their children from preschool institution. For confidentiality reasons, the questionnaire was placed in an envelope. Time allowed to fulfil the questionnaire was about a week. After completing the questionnaire parents were instructed to submit the questionnaire in closed envelopes.

\section{Result Analysis}

The study results generally indicate that there is cooperation between the family and preschool institution, but this cooperation is more a formal cooperation and not very well structured. This is noticed starting from the way in which the working program is chosen.

Table 2. Participation of parents in choosing the working program

\begin{tabular}{ccccc}
\hline & Frequency & Percentage & Valid Percentage & Cumulative Percentage \\
\hline Yes & 7 & 10.9 & 10.9 & 10.9 \\
No & 57 & 89.1 & 89.1 & 100.0 \\
Total & 64 & 100.0 & 100.0 & \\
\hline
\end{tabular}

As shown in Table 2, frequency of parents' participation in choosing the working program is quite low. By this participation of parents one may not expect a constructive and stable cooperation due to the mere fact that they do not feel being part of the working process, which in the working practice in the Institution may be considered that: the parent does not consider himself/herself responsible to participate actively in the work taking place in the institution. This might happen because from the start the possibility of choosing the working program was not made clear for the parents by presenting the working program. Presentation on the philosophy and the working program should be more open to parents so then their active engagement is required. 
Table 3. Who initiates the cooperation between preschool institution and family

\begin{tabular}{cccccccc}
\hline & $\begin{array}{c}\text { The } \\
\text { educator }\end{array}$ & Both parties & No answer & The parents & $\begin{array}{c}\text { No } \\
\text { cooperation initiative }\end{array}$ & Total \\
\hline Preschool Institution (1) Urban area & 3 & 11 & 2 & 1 & 1 & 18 \\
Preprimary Classes -(2)Rural Area & 2 & 10 & 2 & 0 & 0 & 14 \\
Preschool Institution (3) Urban Area & 7 & 16 & 6 & 1 & 2 & 32 \\
Total & 12 & 37 & 10 & $\mathbf{2}$ & 3 & 64 \\
\hline
\end{tabular}

Table number 3 shows that there is no significant difference between the initiation of cooperation both in preschool institutions in urban areas and rural areas. According to parents, cooperation is initiated by both sides. This statement by parents draws a conclusion that there is no plan on organizing cooperation, through which activities would be coordinated both by institution and parents. Cooperation is spontaneous mostly and depends on situations arising in the institution.

While many studies argue that communication is the best way to create sustainable connection with parents in order to create a general culture of cooperation. Parents were also asked what is the most frequent form that they use to communicate with teachers and discuss with them regarding their children. Parents have underlined as the most often form is time when they pick-up and drop-off their children from the institution.

Table 4. Forms of communication considered as the most appropriate ones by parents

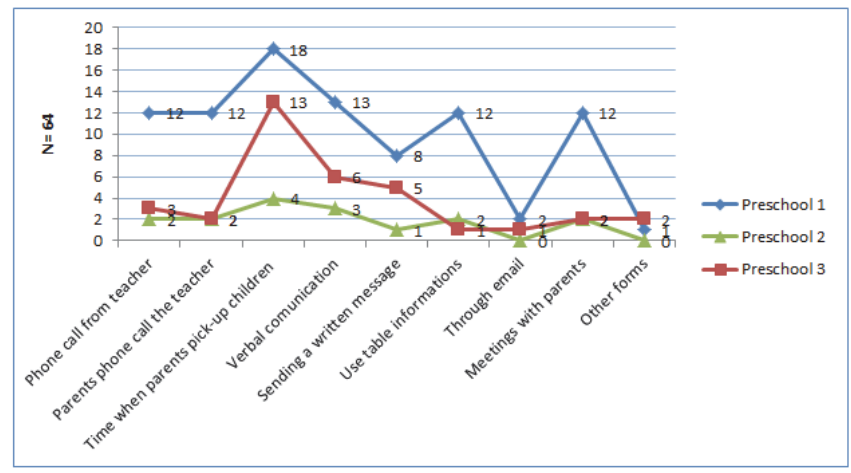

It is important to note that although this form of communication is seen as the most favourable by parents, this is a relatively short time to establish a stable cooperation relationship between the family and preschool institution. Having in mind that children arrive in the institution and leave it at roughly the same time it is clear that we cannot have a sustainable and long-term cooperation if this form of communication is not expanded and supplemented by other forms. Since in rural areas many children go to pre-primary classes alone or accompanied by sisters or brothers going to the same school, it's impossible for the educator to meet the parents for short periods of time. Therefore this form of communication applied alone cannot be considered stable and in the function of child development.

Among other forms considered as appropriate and practical by parents are telephone calls by educator or by parents themselves. It is a form which creates a greater flexibility for parents because it does not require for their physical presence at a certain time. But this form may not be quite appropriate for educators considering that a group in preschool education is expected to have an average of 24 children.

Messages, information boards are another form which is seen as practical but probably not to the extent it should or expected to be. Since the number of parents who stated that the kindergarten uses such a form of communication is relatively limited.

In general, from the findings of this study we may say that the climate of communication with parents from the parent's point of view varies from institution to institution and from that depends also the cooperation that these institutions will have with parents and their involvement in the activity taking place in the institution. Be that a direct involvement in activities or other assistance required in the institution. 
Table 5. What is your participation form as a parent in preschool institution?

\begin{tabular}{|ll|c|c|c|c|}
\hline & & $\begin{array}{c}\text { Preschool } \\
\text { Institution (1) }\end{array}$ & $\begin{array}{c}\text { Pre-Primary } \\
\text { Class (2) }\end{array}$ & $\begin{array}{c}\text { Preschool } \\
\text { Institution (3) }\end{array}$ & Total: \\
\hline $\begin{array}{ll}\text { What is your participation } \\
\text { form as a parent in } \\
\text { preschool institution? }\end{array}$ & Based in the preschool needs & 3 & 4 & 13 & 20 \\
& $\begin{array}{l}\text { Buying preschool books for our children } \\
\text { Being part of the activities in class }\end{array}$ & 9 & 4 & 8 & 21 \\
& $\begin{array}{l}\text { Participation in celebrations, other activities in } \\
\text { preschool, etc. }\end{array}$ & 3 & 0 & 1 & 2 \\
& $\begin{array}{l}\text { Participation in celebrations } \\
\text { We don't have the possibility to participate }\end{array}$ & 0 & 0 & 5 & 5 \\
& Other & 2 & 5 & 5 & 12 \\
\hline Total & 1 & 0 & 0 & 1 \\
\hline
\end{tabular}

As shown in Table 5, participation of parents in activities taking place in the kindergarden is relatively small. From the total number of parents $N=64$ involved in the study, only $32 \%$ of them $(N=21)$ are more involved in the activity taking place in the institution.

If we analyse the quality of participation of parents, then we see that their participation is not directly related to the learning or game activities that take place in preschool institutions, mainly their involvement is indirect. Of the total number of participants in the study $(N=64), 20 \%$ of them $(N=13)$ have never been involved in any way in the preschool institution.

\section{Discussion}

This study addresses the development of cooperation between parents and educators in public preschool institutions. A good cooperation begins with a good and bilateral communication aiming on creating an environment suitable for healthy growth of child. As Kocyigit (2015) emphasises, for having a crucial role in aiding early child development, families and preschool institutions need to act together.

Low participation of parents in choosing the working program may be seen as one of the main barriers that impedes or prevents the active involvement of parents. There are a number of factors that may impact, such as tradition, cultural aspect, but also according to Hyson (2008) negative experiences with schools or teachers, either in their own grow-up or when their children were enrolled in other programs (p. 114). And that is something that increases the responsibility of the Institution on how to develop communication, the forms to be used or how to promote sustainable cooperation with parents.

Leithwood also states that "communication ought to be a two-way street. It also needs to be frequent, take multiple forms, and arise at least in part from a careful assessment of what it is that parents want information about" $(2009$, p.13) (1999, p.13).

From result analyses, the most common way of communication as seen by parents is the time when they drop-off and pick-up their children from the institution. Hornby (2011) argues that "the actual strategies used by schools should respond to parent preferences. Therefore, it is considered that making a range of strategies available to parents will lead to optimal levels of parental involvement in schools. However, the range of strategies used by schools will mostly be dependent on teachers' knowledge and skills for effectively implementing the various strategies" (p.98). Each form of communication seen appropriate by parents should be enforced and expanded by institutions by drafting an action plan or strategy which will allow institutions to take into account the requests, possibilities and skills that parents may have and to involve them in activities taking place in the institution.

Active involvement of parents in the activity developed in the institution has multiple effects, according to Henrich \& Blackman-Jones (2006). parent involvement in preschool is linked to children's academic achievement through multiple pathways, thereby boosting the power of well-designed preschool programs to foster the school readiness of children from low-income families. Also the research from Sandberg \& Vuorinen (2008) mentions that the successful cooperation between home and preschool can contribute to individual children's problems being noticed and attended to in time. From the results of this study we may conclude that family involvement is not satisfactory, therefore more work needs to be 
done in this regard, by understanding clearly its long-term benefits for a child as an individual but also for the whole society.

\section{Conclusion}

We cannot talk about holistic development of a child if there is no stable and long-term cooperation between preschool institutions and family. From the study we may conclude that preschool institutions should use various forms of communication with the family, taking into account the cultural and social context in which the family lives.

Institutions should play a more active role in initiating the partnership between family, preschool institutions and community. By initiating specific programs for parent involvement at institutional level but also at lower levels, by developing strategies of family and community involvement in the activity taking place in preschool institution.

\section{References}

Epstein, J. L. (2002). School, Family, and Community Partnerships: Caring for the Children We Share. Në J. L. Epstein, M. G. Sanders, B. S. Simon, K. C. Salinas, N. R. Jansorn, \& F. L. Voorhis, School, Family, and Community Partnerships: Your Handbook for Action (bot. i Second Edition, fv. 19-43). Thousand Oaks, CA: Corwin Press.

Epstein, J. L., Sanders, M. G., Simon, B. S., Salinas, K. C., Jansorn, N. R., \& Voorhis, F. L. (2002). School, Family, and Community Partnerships: Your Handbook for Action (bot. i Second Edition). Thousand Oaks, CA: Corwin Press.

Henrich, C. C., \& Blackman-Jones, R. (2006). Parent Involvement in Preschool. In E. Zigler, W. S. Gilliam, \& S. M. Jones, A vizion for universal preschool education (pp. 149-167). Cambridge: Cambridge University Press.

Hornby, G. (2011). Parental Involvement in Childhood Education: Building Effective School-Family Partnerships. New York: Springer.

Hyson, M. (2008). Enthusiastic and Engaged Learners: Approches to Leraning in the Early Childhood Classroom. Teacher College Press and National Association for the Education of Young Children.

Kocyigit, S. (2015, February ). Family involvement in preschool education: Rationale, problems and solutions for the participants. Educational Sciences: Theory \& Practice(15 (1)), 141-157.

Kosovës, K. i. (2006, Janar). Ligji Nr. 02/L-52. Retrieved Janar 15, 2013, from Ligji Nr. 02/L-52 LIGJI MBI EDUKIMIN PARASHKOLLOR: http://www.kuvendikosoves.org/common/docs/ligjet/2006_02-L52_al.pdf

Leithwood, K. (2009). Four key policy questions about parent engagement recommendations from the evidence. Në R. Deslandes (Re.), International Perspectives On Contexts, Communities And Evaluated Innovative Practices: Family-School-Community Partnerships (fv. 8-21). Abingdon, Oxon, RN: Routledge.

MASHT. (2011). Plani Strategjik i Arsimit në Kosovë. Prishtinë.

Rimm-Kaufman, S. E., \& Pianta, R. C. (1999). Patterns of Family-School Contact in Preschool and Kindergarten. School Psychology Review, 28(3), 426-438.

Sandberg, A., \& Vuorinen, T. (2008, June). Preschool-home cooporation in change. International Journal of Early Years Education, 16(2), 151-161. 